\title{
THE EFFECT OF BOUNDARY CONDITIONS ON THE EFFICIENCY OF HEAT OR CONTAMINANT REMOVAL FROM A VENTILATED ROOM
}

\author{
T. V. Tran*, N. T. Thuy \\ VNU University of Science, Hanoi, Vietnam \\ *E-mail: trantv@vnu.edu.vn \\ Received November 26, 2014
}

\begin{abstract}
This paper presents numerical simulations of the convection and diffusion of heat or a contaminant released from a source in a ventilated two-dimensional room with one inlet and one or two outlets. Besides the influential factors on the air flow characteristic such as the Reynolds number $(R e)$ and Grashof number $(G r)$ as well as the geometrical arrangement of the inlet and outlets, the effect of imposing boundary conditions particularly the condition at the outlet upon the air flow is studied numerically in this paper. By imposing an adequate condition for heat/contaminant on the outlet, the steady and near steady solutions of the problem are firstly computed. These solutions allow to evaluate the removal efficiency as well as show the different influence of the zero-value condition from that of the zero-flux one on the air flow characteristic. As shown in this paper, these two boundary conditions have quite different effects on the heat/mass transfer capability of the air flow.
\end{abstract}

Keywords: Boundary condition, removal efficiency, steady, nearsteady solution, flux in, flux out.

\section{INTRODUCTION}

Study of the air flow caused by natural convection or ventilation or both at the same time in enclosed spaces has theoretical interest and practical applications. From theoretical aspect it is interesting to predict what kind of the air motion in the room will be occurred and how much heat or contaminant is removed from the enclosed space depending on the ventilation rate, the intensity and the location of heat or contaminant sources within the enclosure as well as the location of inlets and outlets on the walls. Good knowledge of such flows is essential for designing an efficient ventilation system to save energy as well as provide "healthy" air quality for living or working spaces.

Investigations of the above mentioned problem are based mainly on numerical methods due to its complication. A good and useful presentation of the background from modeling to solving the in-enclosure air flow problem is provided by Pepper and 
Carrington in [1]. As indicated by Qingyan Chen in [2], Computational Fluid Dynamics (CFD) has contributed $70 \%$ of all publications on simulating the air flow in enclosed spaces. Both the Finite Volume Method (FVM) and Finite Element Method (FEM) are mostly used for the CFD-based investigations in this field. The majority of the FVMbased calculations has relied on Semi Implicit Method for Pressure Linked Equation (SIMPLE) algorithm firstly proposed by Patankar [3] or several its modified versions. Sinha, Arora and Subhransu applied this approach to simulate the air flow with buoyancy in a two-dimensional room [4]. Meanwhile Lage, Bejan and Anderson used SIMPLE algorithm for computing the contaminant removal from a ventilated enclosure [5].

Recently researchers have intensively used CFD-commercial packages to obtain numerical solution of the considered here problem. Among these packages FLUENT software is more preferable in numerical simulating three-dimensional air flow in geometrically complicated spaces [6-8]. Besides FVM in this field FEM has been successfully applied too. Lee et al. [9] used FEM to simulate forced and mixed air flow convection in a room. Sumon Saha et al. [10] applied FEM to exhibit the characteristics of mixed convection flows in a cavity.

The air flow in an enclosure is often turbulent except may be for Re low enough motions. For modeling the turbulent air flow in an enclosed space at moderate Re number the $k-\varepsilon$ model proposed by Jones and Launder [11] has been used successfully by many researchers $[5,12]$.

In all of the numerical simulations of laminar or turbulent flow caused by ventilation with or without buoyancy in an enclosure the boundary conditions are usually set as follows. The no-slip condition is applied for the air flow velocity on the solid walls, where the temperature (dimensionless) is assumed to be zero or heat flux vanishes (adiabatic walls). For the case of contaminant the impermeable condition (no contaminant flux) on the rigid walls is always set, that is equivalent to the zero-flux of heat case on such boundaries. In the ventilated enclosure case the velocity and heat or contaminant are taken uniform over the cross-section of the inlet port. All these boundary conditions are adequate to the physical essential of the problem. They are simply natural. It is worth discussing the imposition of the outlet conditions. It seems that all the relevant numerical simulating investigations have applied the no-flux condition for all the flow variables at the outlet. Note that such conditions are less natural than those on the walls and the inlet. They are indeed the computational condition that one usually set on a boundary (of computational domain) far downstream from an object immersed in the flow where all the variables of the flow are assumed to be uniform. In fact, it is not sure in general that all the flow parameters are uniform at the cross-section of the outlet port at any time. The no-flux condition also does not assist to calculate the instant amount of heat/contaminant expelled from the enclosure directly through the outlet. This value is crucial for evaluating effectiveness of every concrete outlet in term of its efficiency in removing heat or contaminant in the case of more than one outlet. In addition by comparing the total amount of heat/contaminant in and out we can distinguish the effect of adopting the zero-value condition for temperature from the zero-flux one on the walls. 
With this aim and for simplicity, in this research laminar air flows in an one inlet two-dimensional room caused by ventilation and a heat/contaminant source are calculated by FEM for several values of $R e$ and $G r$ in three cases: one and two outlets of different size.

\section{PROBLEM FORMULATION}

Consider the two-dimensional room $6 \mathrm{~m}$ long and $3 \mathrm{~m}$ high with the inlet of $1.2 \mathrm{~m}$ in width locating on the left wall at the height $1.2 \mathrm{~m}$ above the ground. A linear heat or contaminant source locates at the middle of the room floor. The length of the source is $0.6 \mathrm{~m}$. Numerical simulations of mixed convection flows in the room are carried out for three cases of the outlet arrangement on the right wall and on the ceiling as shown in Fig. 1. Hereafter the term "heat" is used for the cases with the zero-value condition for temperature $(T)$ on the solid walls. Meanwhile the word "contaminant" refers to the cases of the zero-flux condition for the contaminant concentration $(C)$. Now taking the air inlet velocity $U$, the room height $H$, the ratio $H / U$ and the difference between the inlet temperature (contaminant concentration) and that of the source $\Delta T(\Delta C)$ as characteristic values for velocity, length, time and temperature (contaminant) respectively one can get the following system of the non-dimensional governing equations $[4,13]$

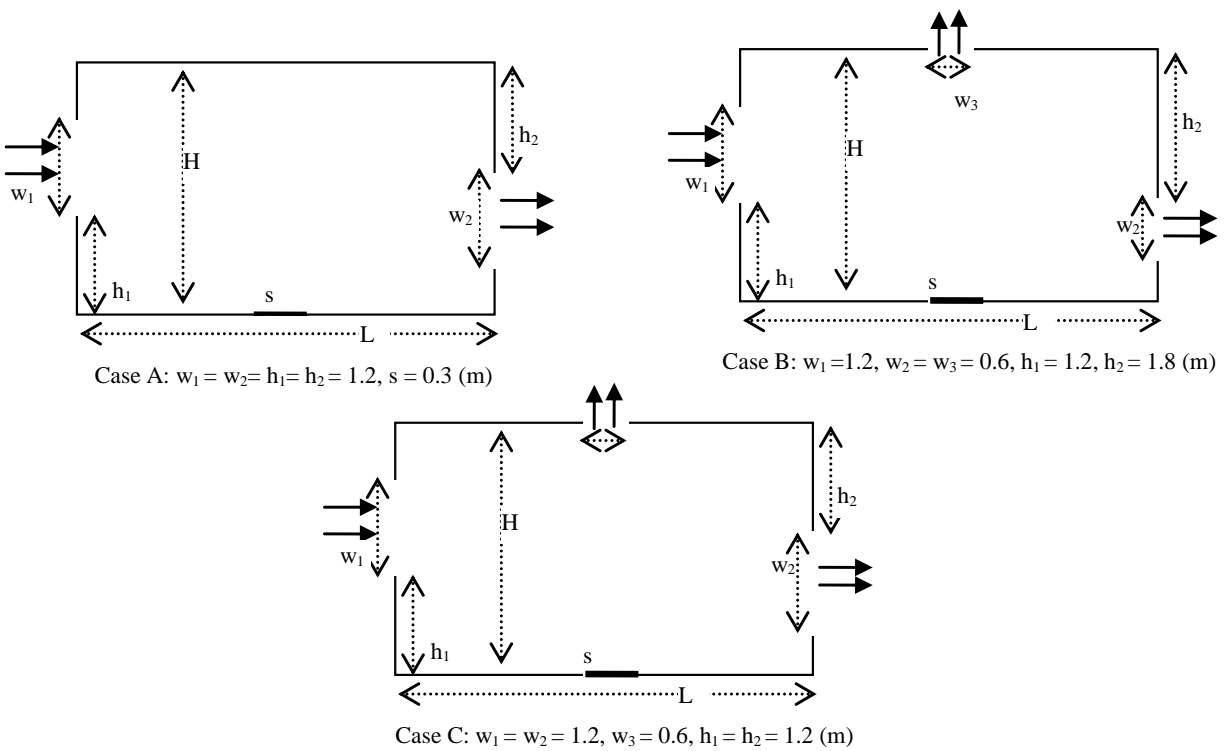

Fig. 1. The geometrical configuration of the room inlet and outlet

$$
\begin{gathered}
\frac{\partial u}{\partial x}+\frac{\partial v}{\partial y}=0 \\
\frac{\partial u}{\partial t}+u \frac{\partial u}{\partial x}+v \frac{\partial u}{\partial y}=-\frac{\partial p}{\partial x}+\frac{1}{R e}\left(\frac{\partial^{2} u}{\partial x^{2}}+\frac{\partial^{2} u}{\partial y^{2}}\right)
\end{gathered}
$$




$$
\begin{gathered}
\frac{\partial v}{\partial t}+u \frac{\partial v}{\partial x}+v \frac{\partial v}{\partial y}=-\frac{\partial p}{\partial y}+\frac{1}{R e}\left(\frac{\partial^{2} v}{\partial x^{2}}+\frac{\partial^{2} v}{\partial y^{2}}\right)+\frac{G r}{R e^{2}} T \\
\frac{\partial T}{\partial t}+u \frac{\partial T}{\partial x}+v \frac{\partial T}{\partial y}=\frac{1}{R e \operatorname{Pr}}\left(\frac{\partial^{2} T}{\partial x^{2}}+\frac{\partial^{2} T}{\partial y^{2}}\right), \\
R e=\frac{U H}{v}, \mathrm{Gr}=\frac{g \beta \Delta T H^{3}}{v^{2}}, \operatorname{Pr}=\frac{v}{\chi}=\frac{v \rho c_{p}}{\lambda} .
\end{gathered}
$$

For the contaminant case in Eqs. (3) and (4) the variable $T$ should be replaced by $C$ whilst $G r$ and $P r$ by the following numbers, respectively,

$$
\mathrm{Gr}_{c}=\frac{g \beta_{c} \Delta C H^{3}}{v^{2}}, S_{c}=\frac{v}{D}
$$

The computational domain ('dimensionless room') now is the rectangular one unit high and two units long.

The boundary conditions are taken as follows.

On the solid walls

$$
\begin{gathered}
u=0, \quad v=0, \\
T=0, \\
\frac{\partial C}{\partial n}=0 .
\end{gathered}
$$

At the inlet

$$
\begin{aligned}
& u=1, v=0, \\
& T=0, C=0 .
\end{aligned}
$$

At the right outlet

$$
u=\bar{w}, v=0 .
$$

At the ceiling outlet

$$
u=0, v=\bar{w},
$$

where $\bar{w}=w_{\text {in }} /\left(w_{\text {ou } 1}+w_{\text {ou } 2}\right)$ with $w_{\text {in }}, w_{\text {ou1 } 1}, w_{\text {ou } 2}$ are the width of the inlet, the wall outlet and the ceiling outlet respectively. Conditions (12) and (13) are imposed to hold the mass conservation of the air flow in the Boussinesq approximation.

At the outlets the below condition is adopted for temperature/contaminant

$$
T_{i}^{n}=T_{i a}^{n-1}, C_{i}^{n}=C_{i a}^{n-1}
$$

where $T_{i a}^{n-1}, C_{i a}^{n-1}$ are the average temperature and contaminant over all the elements of the $i$-th outlet (here the right outlet is the first, the ceiling is the second) at the $(n-1)$ -th time step of the integration respectively. Thus the outlet temperature/contaminant varies in time and its flux must not be zero that is the opposite to usual suggestion. This condition seems to be more natural than the zero-flux one. Even after the air flow becomes steady the flux of $T$ or $C$ at the outlets is still non-zero. In such cases, as indicated in the future, the flux may be unchanged in time when the steady state is established. This flux now is calculated by using condition (14). 


\section{NUMERICAL METHOD}

In this paper the numerical solution of governing equations (1)-(4) with boundary condition (6)-(14) and the initial condition

$$
u=v=T=\left.C\right|_{t=0}=0,
$$

is calculated by FEM. The crucial idea of the FEM procedure applied in this study is CBS (Characteristic Based Split) scheme first proposed by Zienkiewics and Cordina [14] and further developed by Zienkiewicz et al. [15] and by Nithiarasu [16]. This procedure is presented in very good detail in [13].

Before calculating the solution of the above described problem the modified CBS code is used to compute two air flows one presented in [4] and the other in [5]. Fig. 2 shows velocity field (a) and temperature contour (b) for the case B of ref. [4] at $R e=10^{3}$, $G r=10^{8}$ when a two-dimensional room heated by a warm air stream. These pictures are very similar to those presented in Fig. $5 b$ and Fig. $6 b$ of [4]. The average temperature over the room and at the outlet are shown in Fig. 2c. The curve for the room average temperature is slightly smooth whilst the outlet average temperature is slightly oscillating. This oscillation, as discussed later, is caused by the large value of the number $G r$.

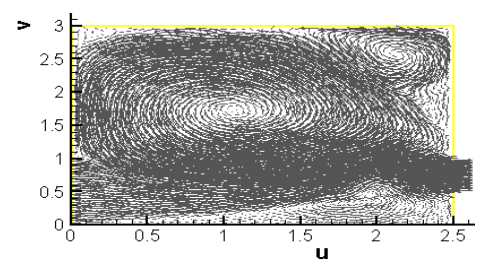

(a)

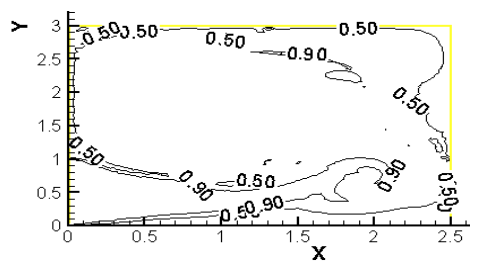

(b)

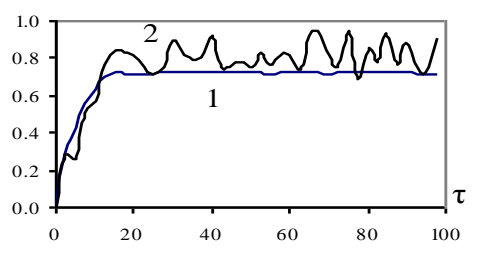

(c)

Fig. 2. Velocity field (a), temperature distribution (b) and variation of average temperature (c): 1- in room, 2- at outlet at $\operatorname{Re}=10^{3}, \mathrm{Gr}=10^{8}$ for case B of ref. [4]

Next consider the problem of the contaminant removal from a ventilated twodimensional enclosure presented in [5]. A contaminant homogenously fills the enclosure of one ceiling inlet at the left and one floor outlet at the right. In [5] the size of the inlet is taken for the characteristic length so the 'dimensionless' enclosure is the rectangular of 20 units long and 10 units high. In this paper the height of the enclosure is the referencing length so the Reynolds number and dimensionless time of [5] are ten times less than $\operatorname{Re}$ and $\tau$ here respectively. Therefore the 'new volume replacement time' $\tau^{*}$ introduced in [5] now relates to $\tau$ by the relationship $\tau^{*}=0.05 \tau$. In Fig. 3 shown the time dependence of the average outlet concentration (a) and the displacement efficiency (b). Note that curve 3 (Fig. 3a) and curve 1 (Fig. 3b) are calculated for $R e=10^{4}$ and $R e=300$ that correspond with values 1000 and 30 of [5] respectively. As indicated in Fig. 3a for $\tau^{*}$ less than 1.25 the outlet average contaminant of this paper slightly greater than that of ref. [5]. The reverse occurs for $\tau^{*}>1.25$. For case the inlet and outlet ports face each other right under 


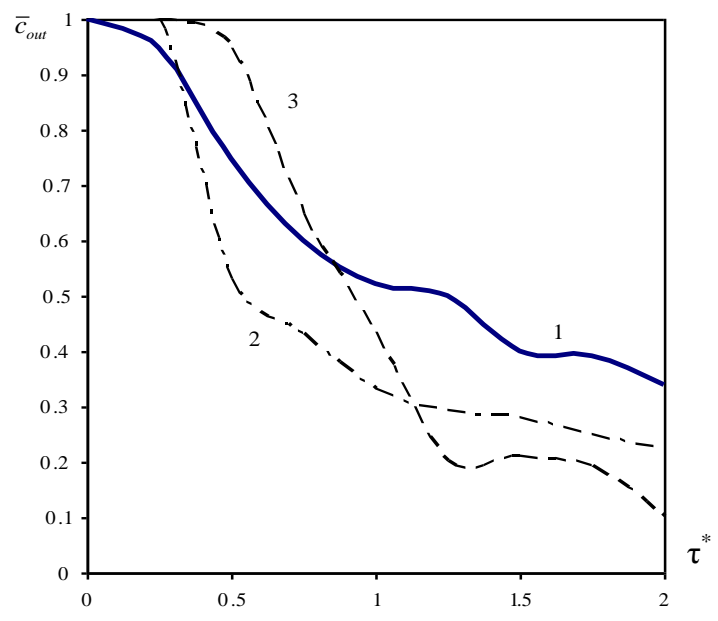

(a)

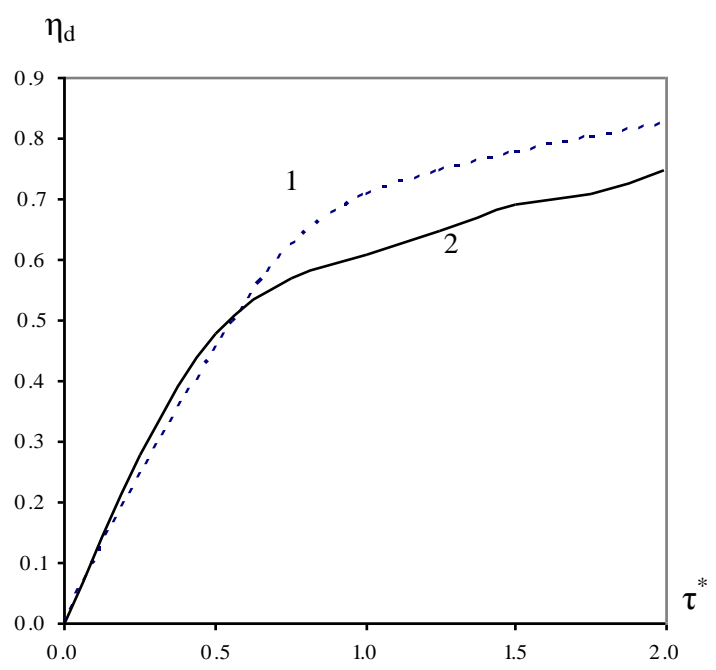

(b)

Fig. 3. (a) Variation of the average outlet concentration (1-experiment data, 2-calculated by ref. [5], 3-this paper) at $R e=10^{3}$, (b) The calculated displacement efficiency at $R e=30$

(1-this paper, 2-from Fig. 7 of ref. [5])

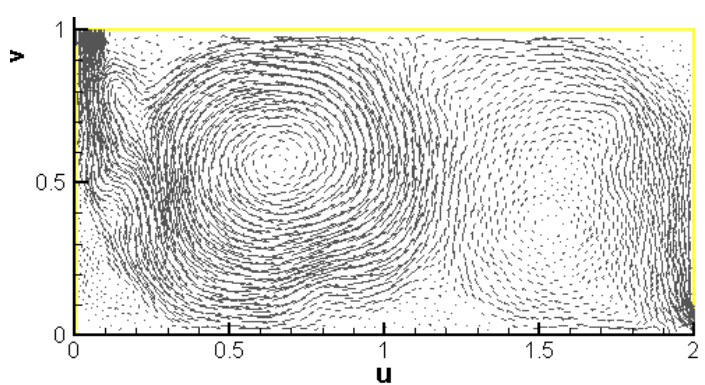

(a)

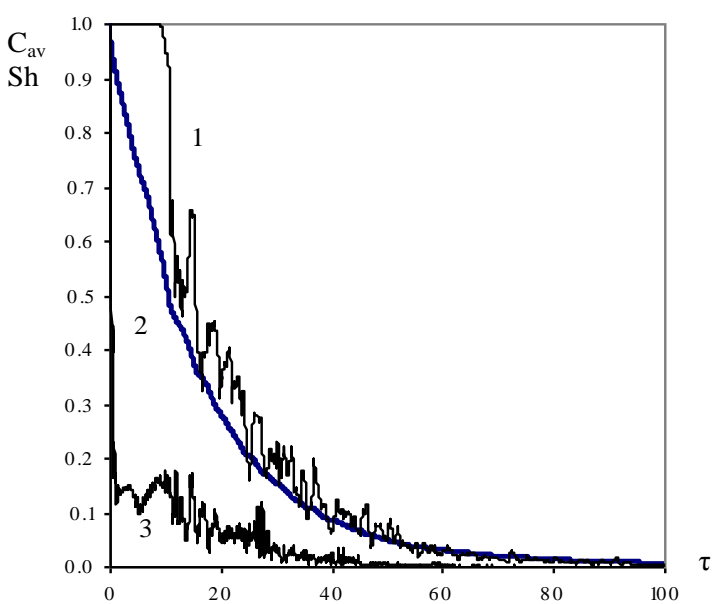

(b)

Fig. 4. Velocity field (a) and variation of the volume and outlet contaminant average at $R e=10^{3}$ for the floor return case of ref. [5]

the ceiling, for $\tau^{*}<0.75$ the calculated efficiency of transient removal of this paper matches perfectly with that of ref. [5] (Fig. 3b). Fig. 4 shows the velocity field and the time dependence of the average contaminant at the outlet (line 1), average contaminant 
over the enclosure (line 2) as well as the flux of contaminant at the outlet (line 3) for the same case of Fig. 3a above. The existence of some circulating zones of the air flow does make both the average outlet contaminant concentration and its flux oscillate. Note that the smoothness of curve 2 as well as its location below curve 1 reflect well what should be expected on the base of the physical understanding of the problem.

\section{RESULTS AND DISCUSSION}

First of all, it is worth noting that in this paper the Prandtl and Smidth number are equal in value and equal 0.71 in all the simulations. This, as mentioned above, helps to elucidate and compare the effect of the boundary conditions on the flow and its removal efficiency of heat or contaminant at the same value of $R e$ and $G r$ for the same room configuration of the outlets. Fig. 5 shows the air velocity field for case A. It is clear that at $\operatorname{Re}=10^{3}$ and $\mathrm{Gr}=10^{5}$ the flow is smooth from the inlet to the outlet (Fig. 5a, Fig. 6a and Fig. 6c). When $R e$ increase to $10^{5}$ some circulation zones appear in the flow (Fig. 5b). The effect of the heat convection on the flow structure is also demonstrated by Fig. 5c when $R e$ is kept low but $\mathrm{Gr}$ grows to $10^{7}$. This effect is more evident for case B of two outlets as shown in Fig. 6b. As expected, the interaction between the ventilation rate and the strength of the heat source makes the flow more complicated than a pure flow caused by only one of these factors. As expected also the increase of $R e$ is more sensitive than that of $\mathrm{Gr}$ to forming vortices of different size. It is necessary to note that the velocity field is not almost effected by the choice between (7) and (9) so here the velocity pictures for the contaminant case are not provided. As seen later the smooth flow is a true steady air motion. All its average values such as the room temperature, outlet temperature, heat flux from the source and heat flux out on the outlet are constant. Meantime the flows with the vortices can be regarded as almost steady motion with all the mentioned above values being fluctuating around some average constant.

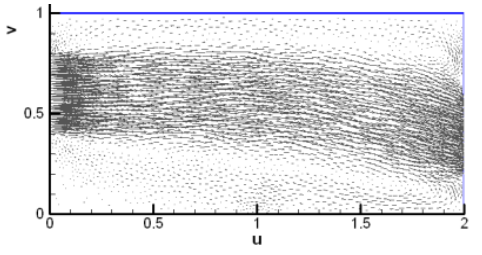

(a)

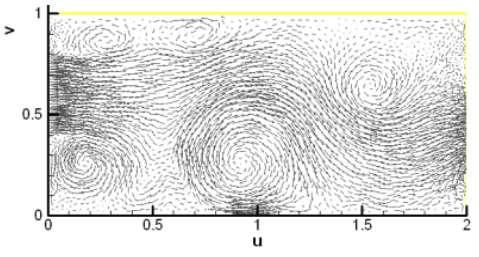

(b)

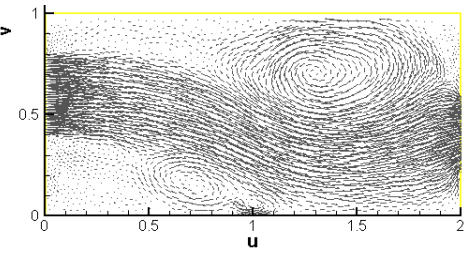

(c)

Fig. 5. Velocity field for case A with the heat source,

(a) $R e=10^{3}, G r=10^{5}$, (b) $R e=10^{5}, G r=10^{5}$, (c) $R e=10^{3}, \mathrm{Gr}=10^{7}$

The simulations of this study show that numerical solutions obtained at $R e=10^{3}$ and $G r=10^{5}$ in all three cases A, B and C become steady after the dimensionless time $\tau$ reaches a value from 20 to 40 . In Fig. 7 shown the temperature or contaminant contour of these solutions. The common characteristic of these steady air flows is the fact that the only zone of the positive temperature/contaminant locates in the left of the source and under the main stream. It is obvious in accordance with the arrangement of the inlet and 


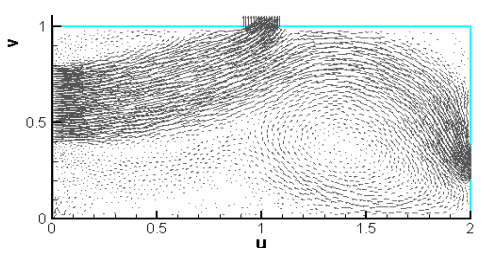

(a)

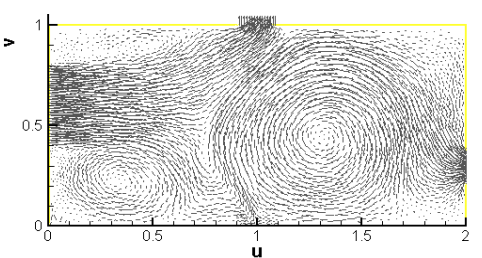

(b)

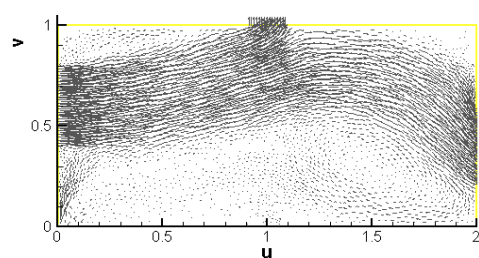

(c)

Fig. 6. Velocity field for case B with the heat source,

(a) $\operatorname{Re}=10^{3}, \mathrm{Gr}=10^{5}$, (b) $\operatorname{Re}=10^{3}, \mathrm{Gr}=10^{7}$ for case $\mathrm{C}$, (c) $\operatorname{Re}=10^{3}, \mathrm{Gr}=10^{5}$

outlets in Fig. 1. Note that also the 'hot' zone in Fig. 7a and Fig. 7c for temperature does not touch the solid walls where on the contrary exist points of even high contaminant concentration (see Fig. $7 \mathrm{~b}$ and Fig. $7 \mathrm{~d}$ ). This fact is in accordance with the nature of conditions (7) and (9).

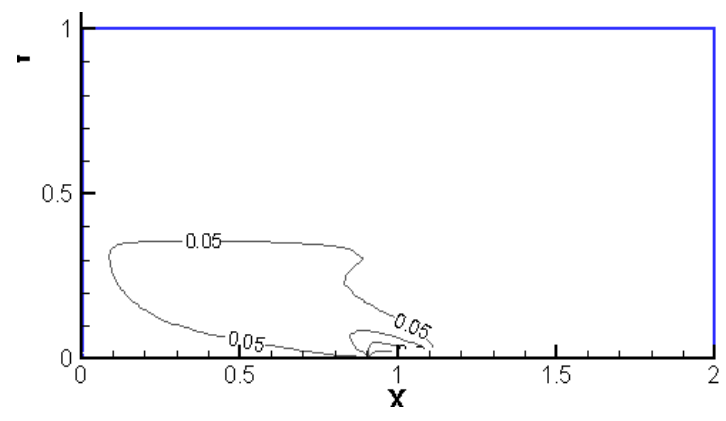

(a)

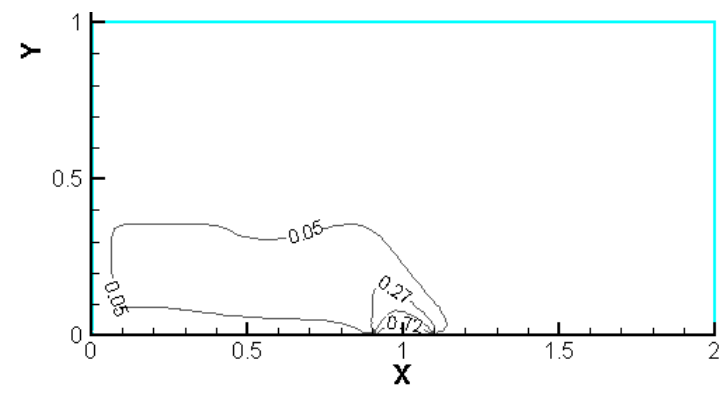

(c)

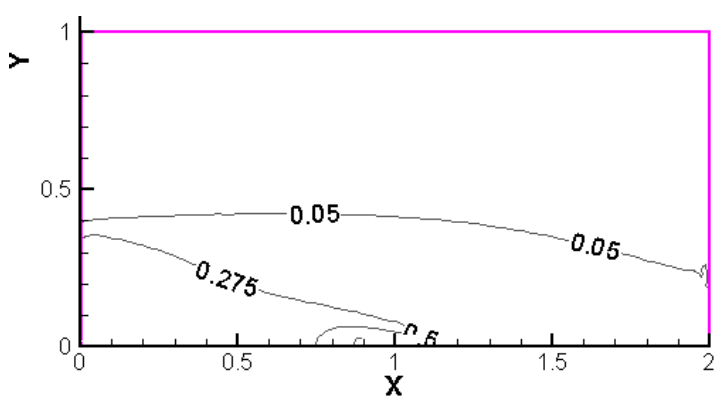

(b)

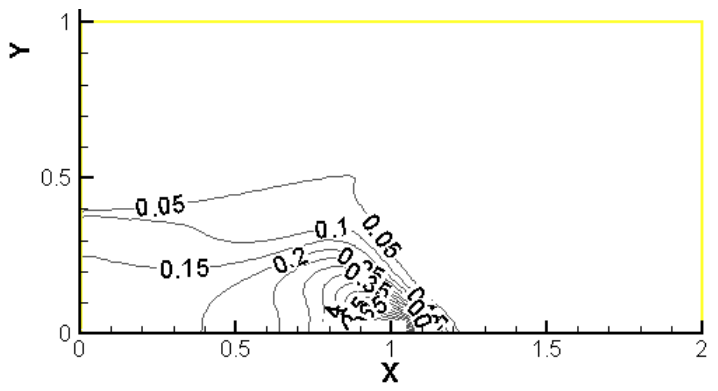

(d)

Fig. 7. Temperature and contaminant contour at $R e=10^{3}, \mathrm{Gr}=10^{5}$, case A: (a)-for heat, (b)-for contaminant, case B: (c)-for heat, (d)-for contaminant

For flows with high Re or high Gr the 'true' steady motion is not likely to exist. Instead of this some fluctuating around a steady average flow takes place. The presence of such flow will be more evident later when the variation of the average temperature or 
contaminant concentration over the room and at the outlet is considered. The existence of some separated zones of non-zero contours, as seen in Fig. 8, is the characteristic feature for this kind of flows. This characteristic is the direct consequence of the presence of some circulating motion zone in the air flow. This also explains why in cases of Fig. 2 (with $\operatorname{Re}=10^{3}$ and $\mathrm{Gr}=10^{8}$ ) and Fig. 3 (with $\operatorname{Re}=10^{3}$ ) the outlet average temperature or contaminant oscillates even there is not any source in the enclosure.

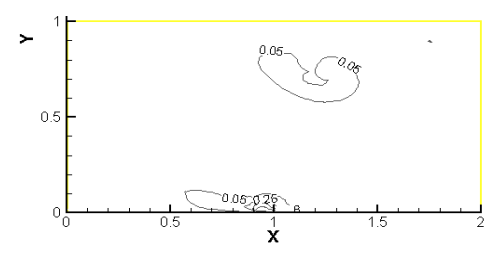

(a)

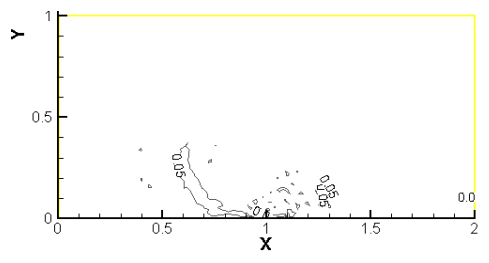

(b)

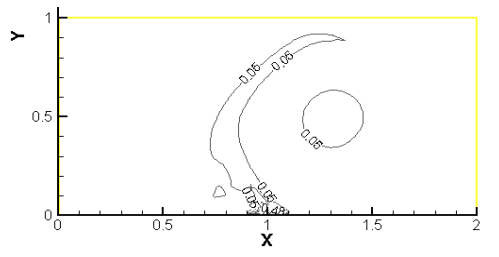

(c)

Fig. 8. Temperature contour for case A: (a) at $\operatorname{Re}=10^{3}, \mathrm{Gr}=10^{7}$, (b) at $R e=10^{5}, G r=10^{5}$, for case B: (c) at $R e=10^{3}, G r=10^{7}$

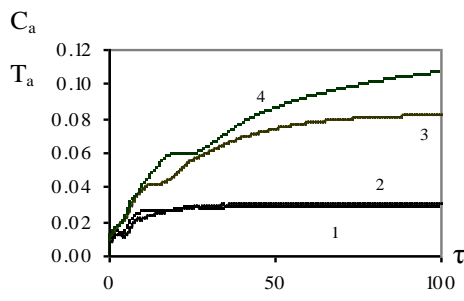

(a)

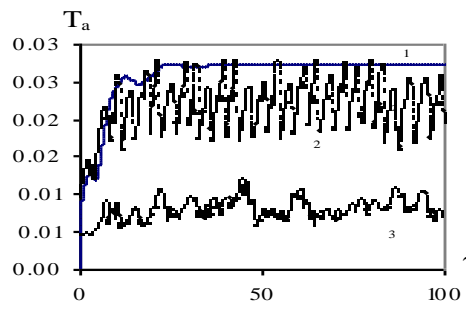

(b)

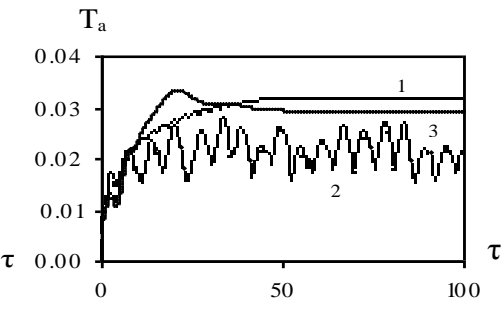

(c)

Fig. 9. (a) Variation of the room average temp./cont. at $R e=10^{3}, \mathrm{Gr}=10^{5}$ case A (3-temp., 4-cont.), case $C$ (1-temp., 2-cont.), (b) Variation of the average room temperature for case A (1-Re $=10^{3}, \mathrm{Gr}$ $\left.=10^{5}, 2-R e=10^{5}, G r=10^{5}, 3-R e=10^{3}, G r=10^{7}\right)$, (c) Variation of the average room temperature for case B $\left(1-\operatorname{Re}=10^{3}, \mathrm{Gr}=10^{5}, 2-\operatorname{Re}=10^{3}, \mathrm{Gr}=10^{7}, 3\right.$-for case $\left.\mathrm{C}, \operatorname{Re}=10^{3}, \mathrm{Gr}=10^{5}\right)$

Now consider the simulation results focusing on the effect of boundary condition (7) and (9) on the removal efficiency. Fig. 9 proves the existence of steady and almost steady air motion in the room in the dependence upon the Reynolds and Grashof number. Fig. 9a shows the ceiling outlet (case $C$ ) helps to decrease $T_{a}$ and $C_{a}$ in several times in the comparison with case A. The ceiling outlet also assists the flow to reach the steady state faster. As indicated in Fig. 9a condition (7) makes $T_{a}$ slightly less in value than $C_{a}$ of condition (9) in both cases $\mathrm{A}$ and $\mathrm{C}$. The fact that the average temperature of fluctuating flow is less than that of the steady one (lines 2 and 3 lie below line 1 in Fig. 9b) can be explained as follows. In the steady case the main stream locates high enough above the floor (see Fig. 5a) so it takes out less the heat/contaminant released from the floor source. Therefore a significant part of the released heat/contaminant has diffused into the almost 
stagnant zone in the left corner. This heat/contaminant amount does make the room average higher. Meantime the vortices in cases of Fig. 5b and Fig. 5c play very important role in transferring heat/contaminant from the source to the main stream especially in the case of line 3 a big circulating zone at the top right corner makes the main stream adjacent to the source.

Next let analyse heat/contaminant flux from the source and heat/contaminant flux on the outlet. Hereafter for simplicity the first is called as the flux in and the second is named as the flux out. The flux of heat and contaminant is expressed through the Nusselt $(\mathrm{Nu})$ and the Sherwood number $(\mathrm{Sh})$ by the following formulae respectively.

$$
\begin{gathered}
(N u)_{\text {in }}=\int_{S}-\left.\frac{\partial T}{\partial y}\right|_{y=0} d x,(S h)_{\text {in }}=\int_{S}-\left.\frac{\partial C}{\partial y}\right|_{y=0} d x, \\
(N u)_{\text {out }}=\left.\int_{w_{2}} \frac{\partial T}{\partial x}\right|_{x=2} d y+\left.\int_{w_{3}} \frac{\partial T}{\partial y}\right|_{y=1} d x,(S h)_{\text {out }}=\left.\int_{w_{2}} \frac{\partial C}{\partial x}\right|_{x=2} d y+\left.\int_{w_{3}} \frac{\partial C}{\partial y}\right|_{y=1} d x,
\end{gathered}
$$

Fig. 10 shows the variation of heat flux in and out. Its behavior in Fig. 10 strongly convinces the existence of the steady solution (Fig. 10a and b) and the near steady one (Fig. 10c) of the problem. It is important to note that although the flux out is always less than the flux in but the average temperature in the room does not increase unlimitedly in time (see Fig. 9). It is because the flux in depends on the difference between the temperature of the source and that of the air layer adjacent to the source. This difference in its turn depends on the flux out. So in the steady or near steady state the difference between these two fluxes makes the average temperature constant or near constant respectively.

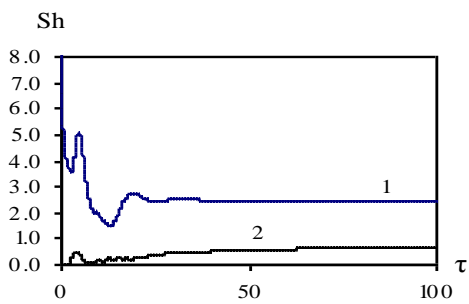

(a)

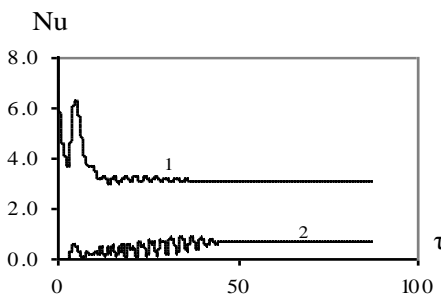

(b)

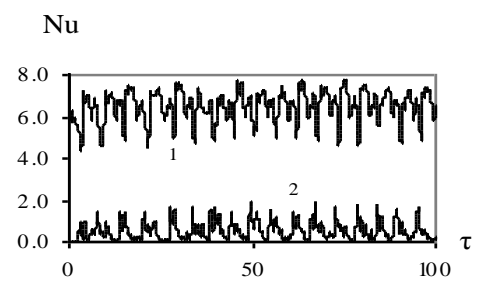

(c)

Fig. 10. (a) Variation of the contaminant flux in and out for case A: 1-in, 2-out at $R e=10^{3}$, $G r=10^{5}$, Variation of the heat flux in and out for case B: (b) 1-in, 2-out at $R e=10^{3}$, $G r=10^{5}$, (c) 1 -in, 2-out at $\operatorname{Re}=10^{3}, \mathrm{Gr}=10^{7}$

Finally consider the effect of conditions (7) and (9) on the flux in and out by analysing the ratios (heat flux/contaminant flux) in and out for the same case and at the same value of $R e$ and $G r$. These ratios are the most clear indicator for distinguishing the influence of the zero-value condition (7) from that of the zero-flux condition (9) on the removal efficiency. Fig. 11 shows the variation of the mentioned above ratios for case A and C. As indicated in Fig. 11 the heat flux in is greater than contaminant one at any moment. 
For flux out it turns opposite. In case A (Fig. 11a) for the steady phase the relationship between fluxes are approximately as follows.

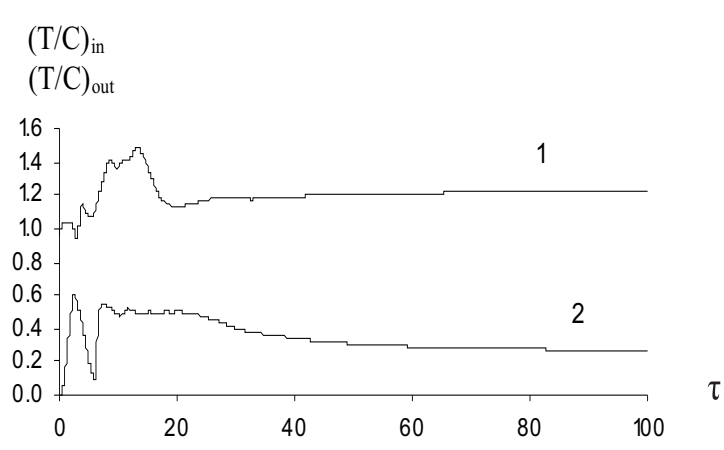

(a)

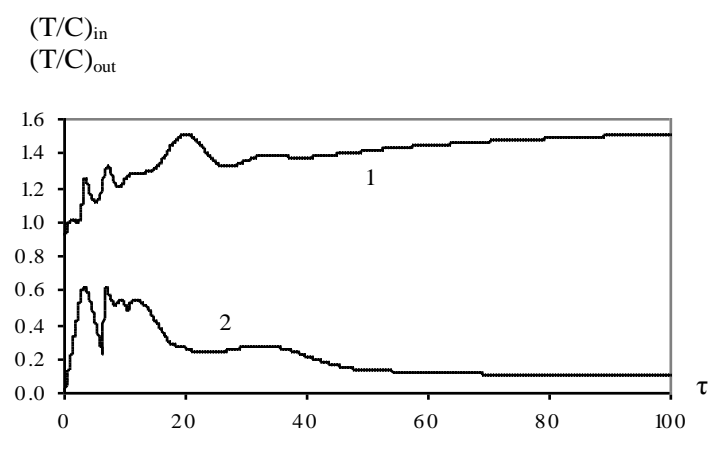

(b)

Fig. 11. (a) Variation of (heat/cont.) in and (heat/cont.) out at $R e=10^{3}, G r=10^{5}$, (a)-for case A: 1-in, 2-out, (b)-for case C: 1-in, 2-out

$T_{\text {in }}=1.3 C_{\text {in }}, T_{\text {out }}=0.3 C_{\text {out }}$

Hence one has: $T_{\text {in }} / T_{\text {out }}=4.3 C_{\text {in }} / C_{\text {out }}$. This proves that the zero-value condition on the solid walls for the heat case implies the assumption that the heat flux on the walls has no restriction.

\section{CONCLUSION}

By imposing an adequate boundary condition for heat/contaminant on the outlet the steady and near steady solutions of the problem of heat/mass transfer for a twodimensional ventilated enclosure with an inside source are found numerically. Furthermore using this boundary condition one can calculate the amount of heat/contaminant taken out by the air flow through the outlets. This allows not only to evaluate the heat/contaminant removal efficiency for different inlet/outlet geometrical arrangement but also quantitatively show the difference in the effect of the zero-value condition and the zero-flux condition on the solid walls upon the removal efficiency.

\section{REFERENCES}

[1] D. W. Pepper and D. Carrington. Modeling indoor air pollution. Imperial College Press, (2009).

[2] Q. Chen. Ventilation performance prediction for buildings: A method overview and recent applications. Building and Environment, 44, (4), (2009), pp. 848-858.

[3] S. V. Patankar. Numerical heat transfer and fluid flow. Hemisphere, Washington, DC, (1980).

[4] S. L. Sinha, R. C. Arora, and S. Roy. Numerical simulation of two-dimensional room air flow with and without buoyancy. Energy and Buildings, 32, (1), (2000), pp. 121-129.

[5] J. L. Lage, A. Bejan, and R. Anderson. Efficiency of transient contaminant removal from a slot ventilated enclosure. International journal of heat and mass transfer, 34, (10), (1991), pp. 26032615. 
[6] G. Gan. Interaction between wind and buoyancy effects in natural ventilation of buildings. Open Construction and Building Technology Journal, 4, (2010), pp. 134-145.

[7] M. Arya and S. P. S. Rajput. Monitoring and analysis of indoor air quality at different heights in industrial room by using CFD. International Journal of Environmental Sciences, 1, (6), (2011), pp. 1062-1071.

[8] D. Prakash and P. Ravikumar. Simulation of indoor air flow for a room with windows at their adjacent walls under various wind flow direction using CFD. ARPN Journal of Engineering and Applied Sciences, 7, (11), (2012), pp. 1387-1394.

[9] S.-C. Lee, C.-Y. Cheng, and C.-K. Chen. Finite element solutions of laminar and turbulent flows with forced and mixed convection in an air-cooled room. Numerical Heat Transfer, Part A Applications, 31, (5), (1997), pp. 529-550.

[10] S. Saha, M. N. Hasan, and I. A. Khan. Double diffusive mixed convection heat transfer inside a vented square cavity. Chemical Engineering Research Bulletin, 13, (1), (2009), pp. 17-24.

[11] W. P. Jones and B. E. Launder. The prediction of laminarization with a two-equation model of turbulence. International Journal of Heat and Mass Transfer, 15, (2), (1972), pp. 301-314.

[12] J. L. Lage, A. Bejan, and R. Anderson. Removal of contaminant generated by a discrete source in a slot ventilated enclosure. International Journal of Heat and Mass Transfer, 35, (5), (1992), pp. 1169-1180.

[13] R. W. Lewis, P. Nithiarasu, and K. N. Seetharamu. Fundamentals of the finite element method for heat and fluid flow. John Wiley \& Sons, (2004).

[14] O. C. Zienkiewicz and R. Codina. A general algorithm for compressible and incompressible flow-Part I. the split, characteristic-based scheme. International Journal for Numerical Methods in Fluids, 20, (8-9), (1995), pp. 869-885.

[15] O. C. Zienkiewicz, P. Nithiarasu, R. Codina, M. Vazquez, and P. Ortiz. The characteristicbased-split procedure: an efficient and accurate algorithm for fluid problems. International Journal for Numerical Methods in Fluids, 31, (1), (1999), pp. 359-392.

[16] P. Nithiarasu. An efficient artificial compressibility (AC) scheme based on the characteristic based split (CBS) method for incompressible flows. International Journal for Numerical Methods in Engineering, 56, (13), (2003), pp. 1815-1845. 